\title{
Direitos reprodutivos: debates e disputas sobre o direito ao aborto no contexto da redemocratização do Brasil
}

\author{
Myriam Aldana ${ }^{1}$ \\ Silvana Winckler
}

Sumário: Introdução; 1. O surgimento dos direitos reprodutivos; 2. O debate sobre o aborto no âmbito dos poderes Legislativo, Executivo e Judiciário; Referências.

\begin{abstract}
Resumo: O processo de redemocratização do Brasil, após vinte anos de regime militar (19641984), trouxe à tona uma série de demandas de direitos até então não reconhecidos, reivindicados por novos movimentos sociais pautados em temáticas identitárias (gênero, etnia, classe etc.). Neste cenário situam-se as manifestações pró e contra o reconhecimento do direito ao aborto enquanto dimensão dos direitos reprodutivos, perpassando espaços institucionais, como os poderes Legislativo, Executivo e Judiciário, e mobilizando diferentes setores da sociedade civil, além das Igrejas, que vêm jogando um papel fundamental nesse processo. Este texto apresenta elementos desse debate, no intento de afirmar os direitos reprodutivos como direitos humanos.
\end{abstract}

Palavras-chave: aborto; direitos reprodutivos; direitos sexuais.

\begin{abstract}
The process of redemocratization of Brazil, after twenty years of a military regime (1964-1984), brought within it several rights which had never been recognized, defended by new social movements based on identity issues (gender, ethnic, social class, etc.). Manifestations (for and against) the recognition of the right to abortion as a dimension of the reproductive rights cross institutional spaces, such as the Legislative, Executive and Judicial powers, and mobilize different sectors of the civil society (besides churches), which have been playing a fundamental role in this process. This article presents some elements of this debate, aiming to affirm the reproductive rights as human rights.
\end{abstract}

Keywords: abortion; reproductive rights; sexual rights.

1 Myriam Aldana V. Santin, Graduação em Sociologia, Mestrado em Ciências da Religião pela Universidade Metodista de São Paulo (1994) e Doutorado Interdisciplinar em Ciências Humanas pela Universidade Federal de Santa Catarina (2005). Atualmente é professora titular da Universidade Comunitária Regional de Chapecó. Tem experiência na área de Ciência Política, com ênfase em Políticas Públicas e Cidadania, Relações de Gênero, atuando principalmente nos seguintes temas: Igreja Católica, direitos sexuais e direitos reprodutivos, religião, direitos das mulheres, aborto. 


\section{Introdução}

O debate sobre a política demográfica aconteceu no Brasil a partir da segunda metade do ano de 1960 . Nessa época, tal debate girava em torno do controle da natalidade, da necessidade de os países subdesenvolvidos adotarem políticas de regulação dos nascimentos para fazerem frente aos problemas da fome, do subdesenvolvimento, do atendimento às necessidades básicas da população. Um dos aspectos centrais era a legitimidade ou ilegitimidade do Estado em traçar programas de controle da natalidade. Por outro lado, o governo sofria pressões internacionais do Banco Mundial e do Fundo Monetário Internacional para adotar políticas controlistas. Neste contexto, o tema do aborto entra em pauta com certa frequência no Congresso Nacional. De acordo com Rocha (1992, p. 26):

No âmbito das atividades ordinárias do Congresso, o assunto foi objeto de inúmeros pronunciamentos, de diversos projetos de lei, de pareceres, discussões e reuniões públicas nas Comissões Permanentes, além de ter motivado a realização de duas Comissões Parlamentares de Inquérito (CPIs).

No debate sobre aborto, os atores principais têm sido sempre a Igreja Católica e o movimento feminista (BARSTED, 1992). O aborto, que continua sendo encarado pela Igreja Católica somente como problema ético, para o movimento de mulheres já passa a ser visto como um dos direitos reprodutivos - pois com ele se determina o grau de domínio que a mulher pode ter sobre seu próprio corpo - e como uma questão de saúde da mulher e de saúde pública. Essa duplicidade de visões tem marcado o debate que se trava no Congresso nacional sobre a reprodução humana no Brasil.

O movimento feminista iniciou suas reivindicações perante a sociedade brasileira na década de 1970, restringindo inicialmente suas demandas às liberdades democráticas (pois o país vivia sob uma ditadura militar desde 1964), às condições dignas de trabalho e aos cuidados com a saúde da mulher. As reivindicações dos aspectos individuais e referentes aos direitos reprodutivos só passam a figurar nos documentos dos encontros feministas a partir da segunda metade da década de 1970. E daí em diante, o direito de optar ou não pela concepção, o direito sobre o próprio corpo e o direito de recorrer à interrupção de uma gravidez indesejada nunca mais saíram da pauta de lutas dos movimentos feministas. 
$\mathrm{Na}$ medida em que a democracia ia sendo restabelecida, em meados dos anos de 1980, voltavam à pauta de debates as questões relativas à regulação da natalidade, mas agora com outro enfoque: a saúde pública e a saúde da mulher. Foi nesse contexto da Nova República (a partir de 1985) que o movimento de mulheres, já com marcas mais "feministas", participou significativamente na regulamentação do Programa de Assistência Integral à Saúde da Mulher - PAISM, aprovado em 1986 (BARSTED, 1997).

Os objetivos programáticos do PAISM estão elencados no ํㅡ 6 dos Textos Básicos de Saúde do Ministério da Saúde e buscam a implantação e ampliação dos serviços públicos, constituindo "um conjunto de ações educativas, preventivas, de diagnóstico, tratamento e recuperação, aplicadas permanentemente e de maneira não repetitiva, tendo como objetivo final a melhoria dos níveis de saúde da população feminina." Destaquem-se, a propósito, as ações relacionadas ao aborto e à gravidez indesejada (KIRIAKOS, 1992).

Em 1987, no processo de elaboração da nova Constituição Federal, os movimentos feministas introduziram nos debates da Assembleia Nacional Constituinte os direitos relativos à vida reprodutiva, dentre os quais estaria o que possibilita a interrupção voluntária da gravidez. Travouse, então, uma batalha entre o movimento de mulheres e uma antiga aliada nas lutas pelos direitos humanos e pela volta à normalidade democrática: a Igreja Católica. O pomo da discórdia era a "inviolabilidade" da vida humana: a Igreja Católica queria estender esse direito para "desde o momento da concepção", enquanto o movimento organizado das mulheres defendia a supressão deste adendo (ÁLVARES, 1990).

O movimento feminista olhava a futura Carta Magna como uma possível vantagem nas lutas que se seguiriam e queria garantir a abertura necessária para o uso de todos os métodos humanamente possíveis de tornar a gravidez um direito e uma opção voluntária da mulher. Neste caso, era preciso garantir, nos Direitos Individuais, o entendimento de que os direitos da mulher estão ligados aos dos nascituros, mas não são inferiores ou dependentes desses. Nesse sentido, justifica-se a luta contra o adendo da "inviolabilidade da vida desde a concepção", que fecharia definitivamente as portas à possibilidade de interrupção voluntária da gravidez.

A batalha na Assembleia Nacional Constituinte foi acirrada, envolvendo grupos feministas e seus organismos representativos, assim 
como magistrados, médicos e grupos religiosos bem organizados. O movimento feminista venceu esse primeiro round, deixando os demais passos para o momento da complementação legislativa da Nova Constituição (ROCHA, 1992).

Antes, porém, de adentrarmos nos debates e disputas sobre o direito ao aborto no Brasil como dimensão dos direitos reprodutivos, convém que situemos o movimento de configuração desses direitos.

\section{O surgimento dos direitos reprodutivos}

A relação do Direito com sexualidade e reprodução é relativamente recente nos debates acadêmicos e nos foros políticos, e pouco presente nas conversas onde prevalece o senso comum, pois aí predominam os tabus sobre tais questões. Podemos encontrar abundante bibliografia sobre saúde sexual e reprodutiva, assim como sobre questões relativas ao planejamento familiar, principalmente quando estão ligadas à problemática demográfica. Mas as questões de direito nessa área só se perfilam como um debate a partir da segunda metade do século XX. E, nessa temática, os direitos reprodutivos têm mais história que os direitos sexuais.

O termo Direitos Reprodutivos foi desenvolvido pelo Movimento Internacional Feminista. Segundo algumas autoras (CORRÊA, 1995; PETCHESKY, 1994; BARSTED, 1999; PITANGY, 1994; SEN, 1994), há um consenso de que o termo foi elaborado pelas feministas americanas no final da década de 1970, num contexto de debates sobre aborto, contracepção, esterilização. Esse novo discurso circulou nos Estados Unidos através de debates, passando para a Europa através de encontros internacionais, como o de Amsterdam (1984) sobre aborto, esterilização e contracepção e, nessa ocasião, criou-se a rede internacional de direitos reprodutivos constituída majoritariamente por mulheres dos países desenvolvidos, mas também por organismos representantes dos países em desenvolvimento. ${ }^{2}$

É importante destacar que, desde os anos de 1980, já existia uma grande preocupação em diversos países, como Filipinas, na Ásia, e outros

2 Participantes brasileiras informam que, ao longo dos debates, as feministas do Sul defenderam o uso desta terminologia por considerá-la adequada para cobrir as múltiplas necessidades da saúde reprodutiva das mulheres para além da contracepção e aborto (CORRÊA, 1995). 
da América Latina, sobre a saúde das mulheres. No Brasil, por exemplo, o movimento de mulheres já trabalhava com o conceito de "saúde integral da mulher". Isto permitiu que a nova terminologia de direitos reprodutivos se incorporasse com facilidade nas agendas feministas, ao mesmo tempo que sugeria estarem os conteúdos e significados prefigurados nas aspirações e demandas políticas levantadas pelo movimento de mulheres (CORRÊA, 1995).

No caso brasileiro, a legitimação da noção de direitos relacionados à reprodução imprimiu uma marca feminista nos debates da democratização e, sobretudo nos processos que se desenvolveram, desde os anos 80, na arena de formulação de políticas públicas: "Se a história tem mostrado a ingenuidade de separar os direitos reprodutivos dos demais direitos, a experiência recente das feministas brasileiras mostra que o foco nos direitos reprodutivos pode atuar como catalisador da ampliação da consciência crítica" (BARROSO apud ÁVILA; CORRÊA, 1999, p. 78).

$\mathrm{Na}$ perspectiva feminista, estes conceitos, segundo Corrêa e Petchesky (1996, p. 149), envolvem os seguintes aspectos:

Definimos o terreno dos direitos sexuais e reprodutivos em termos de poder e recurso: poder de tomar decisões com base em informações seguras sobre a própria fecundidade, gravidez, educação dos filhos, saúde ginecológica e atividade sexual e recursos para levar a cabo tais decisões de forma segura. Este terreno envolve necessariamente as noções sobre "integridade corporal" ou controle sobre o próprio corpo. No entanto, também estão em questão as relações que se tem com filhos, parceiros sexuais, membros da família, a comunidade e a sociedade como um todo. Em outras palavras, o corpo existe em um universo socialmente mediado.

Esses direitos são marcados pela participação das mulheres como sujeitos da construção de princípios democráticos, pela luta a favor de sua integridade corporal e de sua autonomia nas decisões a respeito de si próprias.

Foi principalmente no mundo do trabalho/produção que as trabalhadoras brasileiras conseguiram direitos ou "cidadania regulada", como diz Santos (1997), pois o Estado brasileiro, na década de 1930, cumpriu o papel de "doador" de direitos através da legislação trabalhista 
(CLT). As mulheres eram contempladas por esses direitos desde que estivessem inseridas no mundo da produção, um espaço de visibilidade. Enquanto isso, o espaço da reprodução continuava oculto à esfera pública e, portanto, distante das esferas de cidadania.

Na década de 1960, uma nova concepção de pessoa/identidade, marcada pelos traços da subjetividade, da autorealização e da autonomia, forçou as reivindicações de direitos à decisão sobre a vida reprodutiva e cunhou as palavras de ordem que se tornariam emblemáticas na luta das mulheres nas décadas posteriores: "Nosso corpo nos pertence". Este lema vem marcado com várias características da pós-modernidade, na medida em que retrata as tendências da superação dos universalismos e da atenção às individualidades e às diferenças culturais, do abandono do estoicismo cristão à busca incessante do prazer, dos princípios universais da moral estabelecida à autonomia das morais dos diversos grupos sociais. E, como afirmam Ávila e Gouveia (1996, p. 63),

[...] situamos a temática dos direitos reprodutivos e dos direitos sexuais numa articulação feita de vários pontos de tensão, dentre os quais destacamos: relações público/privado; sexualidade/ reprodução; direito como ação normativa e reguladora/liberdade; universalização/fragmentação; Estado/indivíduo.

Como diz Petchesky (1999, p. 31), não se trata de direitos individualistas, mas de direitos que se relacionam com autodeterminação em matéria de procriação e sexualidade. Ter direitos reprodutivos quer dizer ter controle de nossos corpos e de nossas vidas, estarmos livres de maltrato e ter liberdade de expressar-nos sexualmente. Mas tais direitos só podem tornar-se efetivos se forem proporcionadas as condições para desfrutá-los, ou seja, direitos sexuais e reprodutivos devem englobar o atendimento às necessidades sociais que permitam uma opção sexual e reprodutiva real para a maioria das mulheres do mundo, que são pobres.

Para tanto, faz-se absolutamente necessário que os conceitos relativos a esses direitos se ampliem e aprimorem, repercutindo, assim, em aspectos da vida pessoal, familiar, cultural e sociopolítica que, de forma tangencial ou decisiva, estão ligados ao exercício efetivo desses direitos. Parte dessas imbricações já aconteceram ou estão ocorrendo e mostrando seus frutos, como afirma Petchesky (1996, p. 164): 
[...]. Podemos considerar também que o aprimoramento desse conceito trouxe uma nova perspectiva para a idéia de liberdade reprodutiva no sentido de não mais contrapor a contracepção e o aborto a uma maternidade obrigatória. Estas questões são reelaboradas como espaços de vivência da cidadania, e a gravidez e o parto vividos com segurança e dignidade tornam-se temas fundamentais na busca desses direitos [....]. Os direitos reprodutivos podem trazer uma enorme contribuição para repensar de maneira humanizada o processo de transformação das relações sociais. Eles devem ser pensados e trabalhados em conexão com outros campos de direitos e outros instrumentos de mudança social.

Corrêa e Petchesky (1996) sugerem que "as bases para os direitos sexuais e reprodutivos das mulheres consistam de quatro princípios éticos: integridade corporal, autonomia pessoal, igualdade e diversidade". Vejamos brevemente o significado destes princípios:

\section{Integridade corporal}

Este princípio nos deve levar a entender que os direitos sexuais e reprodutivos, além de necessariamente sociais, são irredutivelmente pessoais, pois, em última instância, o seu lugar é o corpo individual das mulheres.

Segundo nossas autoras (p. 161)

[...] a integridade corporal inclui, negativamente, tanto o direito da mulher de não ser alienada de sua capacidade sexual e reprodutiva, quanto o direito à integridade de sua pessoa física. E, positivamente, o direito a usufruir inteiramente de seu potencial corporal - para a saúde, procriação e sexualidade.

\section{Autonomia pessoal}

Trata-se, fundamentalmente, de ouvir as mulheres que, como mulheres, opinam sobre as políticas públicas que dizem respeito a sua saúde sexual e reprodutiva - ouvir as organizações de mulheres sempre que se quer traçar e implementar políticas de ampliação ou de garantia do exercício dos direitos sexuais e reprodutivos. 
Segundo Hervieu-Leger (1999, p. 299), autonomia é uma das características da modernidade:

A modernidade de uma sociedade avalia-se essencialmente pela posição que atribui, em todos os registros da atividade humana, à autonomia do sujeito, isto é, à capacidade que cada indivíduo tem para determinar, em consciência, as orientações que entende dar à própria vida. Ao mesmo tempo, implica que os indivíduos sujeitos tenham condições de definir, debatendo com outros indivíduos sujeitos (entre "cidadãos") as orientações da sociedade na qual vivem. Em tal sociedade, que é necessariamente uma sociedade diferenciada e pluralista, nenhuma instituição poderá pretender impor ao conjunto dos indivíduos e do corpo social um código de sentido global. Em tal sociedade, o sentido da ação individual e coletiva não é recebido de cima, mas construído individual e coletivamente. Tal é, em todo caso, o ethos de nossa modernidade democrática.

\section{Igualdade}

Desde a perspectiva dos Direitos Sexuais e dos Direitos Reprodutivos, a igualdade faz referência às relações entre homens e mulheres e a igualdade entre as mulheres. Esta diferenciação provém, de um lado, das diferenças entre as formas como homens e mulheres participam da vida reprodutiva e da sexualidade de acordo com as desigualdades de gênero que perpassam as concepções de sexualidade, conjugalidade, maternidade, dentre outras, e de outro lado, da garantia da tomada de decisões na vida sexual e reprodutiva sem discriminação de classe, raça, origem étnica, idade, estado civil, orientação sexual, nacionalidade.

\section{Diversidade}

A linguagem universalizante dos instrumentos internacionais de direitos humanos, própria da tradição liberal ocidental, precisa ser reformulada de acordo com as diversas culturas, etnias, raças, e mesmo que se defenda a aplicabilidade universal dos direitos sexuais e reprodutivos tem-se que admitir que estes só terão validade levando-se em conta os diferentes contextos culturais e sociais. 
Identificar estes princípios éticos tem como finalidade criar a possibilidade de refletir sobre o sentido dos Direitos Sexuais, dos Direitos Reprodutivos, como direitos humanos. São universais porque abarcam todos os seres humanos desde seu nascimento; são interdependentes, porque se conectam com todos os demais direitos humanos, e são indivisíveis, porque são vividos e atuam de um modo conjunto e integral.

Neste sentido, nas últimas décadas ocorreram foros e conferências internacionais, tais como a Conferência Internacional sobre População e Desenvolvimento realizada no Cairo em 1994 e a Conferência das Nações Unidas sobre a Mulher, Beijing, 1995, que tiveram como preocupação central a eliminação de todas as formas de discriminação contra a mulher, defendendo e explicitando seus direitos, inclusive os sexuais e reprodutivos, proclamados em Beijing nos seguintes termos:

\begin{abstract}
Os direitos humanos das mulheres incluem seu direito a ter controle sobre as questões relativas à sexualidade, incluída sua saúde sexual e reprodutiva, e decidir livremente a respeito dessas questões, sem se verem sujeitas à coerção, à discriminação ou à violência. As relações sexuais e a reprodução, incluído o respeito à integridade da pessoa, exigem o respeito e o consentimento recíprocos e a vontade de assumir conjuntamente a responsabilidade das conseqüências do comportamento sexual. (Nações Unidas: Plataforma de Ação de Pequim, Seção C - Parágrafo 97).
\end{abstract}

As decisões tomadas nessas instâncias foram assinadas pela maioria dos governos do mundo. O Brasil participou e se comprometeu com esses acordos. Entretanto, continua com um alto índice de mortalidade materna (141 mortes por cem mil nascidos vivos), sendo que o aborto clandestino constitui ainda a quarta causa de mortalidade de gestantes. A violência doméstica e sexual continua presente nos lares e casas noturnas; há um incremento considerável nos índices de mulheres portadoras do HIV contaminadas em seus próprios lares. Tudo isso é reflexo de que os direitos humanos das mulheres, incluindo os sexuais e reprodutivos, continuam sendo desrespeitados. ${ }^{3}$

\footnotetext{
3 Talvez esta situação seja responsável pela proliferação de Projetos de Lei a respeito dessas temáticas tramitando no Congresso Nacional. Em 1998, tramitavam no CN 198 proposições relativas aos direitos das mulheres: 48 delas diziam respeito à área de saúde e sexualidade; 43 tratavam do trabalho da mulher e 38 projetos eram relativos aos direitos
} 
Mas, se por um lado, há uma listagem enorme de ações parlamentares inscritas nos anais do Congresso Nacional, por outro, a tramitação e aprovação de matérias na área da vida sexual e reprodutiva de brasileiros e brasileiras é extremamente parca. Tanto é verdade que os poderes Executivo e Judiciário acabaram tomando duas iniciativas relacionadas à interrupção da gravidez em casos especiais e contemplados em Projetos de Lei com longo tempo de tramitação no Congresso Nacional: a edição, em 1998, de Norma Técnica pelo Ministério da Saúde para "Prevenção e Tratamento dos Agravos Resultantes da Violência Sexual contra Mulheres e Adolescentes" e a liminar concedida em 2004 pelo Supremo Tribunal Federal referente à interrupção da gravidez em caso de feto anencefálico. ${ }^{4}$

\section{O debate sobre 0 aborto no âmbito dos poderes Legislativo, Executivo e Judiciário}

Quer-se apresentar, na sequência, a complexidade e a dinâmica acirrada que envolvem a discussão sobre o aborto como dimensão dos direitos reprodutivos. O tema vem mobilizando diferentes setores da sociedade, dividindo opiniões e evidenciando interesses conflitantes.

A década de 1990 foi marcada pela luta pela descriminalização do aborto (Projeto de Lei $\mathrm{n}^{\circ} 1.135 / 91$ ) e pela regulamentação das hipóteses de aborto legal previstas desde 1940 no Código Penal brasileiro (Projeto de Lei no 20/91). Entraram em cena outras personagens, principalmente organismos ligados à saúde, como os conselhos regionais de medicina, pois a problemática do aborto clandestino passou a interferir nas organizações de saúde e a ser notícia em órgãos importantes de comunicação social, e não só preocupação dos movimentos feministas.

\footnotetext{
humanos e à violência contra a mulher. Já em 2001, o boletim FÊMEA trazia os seguintes números: 23 a respeito de projetos relativos à saúde materna; 5 sobre reprodução assistida; 16 a respeito da prevenção de doenças sexualmente transmissíveis; 12 relativas à prevenção de doenças relacionadas ao aparelho reprodutor (masculino e feminino); 13 sobre aborto; sobre clonagem e reprodução humana "in vitro" havia 9; sobre educação sexual eram 7, 2 tratavam do planejamento familiar. Cf. BOLETIM FEMEA, 1999, Os direitos das mulheres e o Legislativo no Brasil. Jan/1999. Brasília, 16 p.

4 Segundo dados levantados pela ONG Católicas pelo Direito de Decidir, publicados no seu Informativo no 9 de Julho-Agosto de 2004, durante os três meses em que vigeu a liminar, aproximadamente sessenta mulheres foram beneficiadas pelo direito à antecipação terapêutica do parto de feto anencefálico.
} 
A batalha pela descriminalização do aborto não avançou institucionalmente, mas tampouco retrocedeu. Aumentou seu raio de abrangência, movimentando juristas, médicos, movimentos de mulheres, movimentos de cristãos, teólogos, especialistas em Ética e o Congresso Nacional. Neste, foi longa e acirradamente debatida a PEC 25: uma proposta de Emenda Constitucional (lançada por parlamentares ligados à Igreja Católica) para introduzir no capítulo dos Direitos Individuais, no item sobre a "inviolabilidade da vida humana," o adendo acima mencionado "desde o momento da concepção". A proposta não conseguiu aprovação na Comissão de Constituição, Justiça e Redação e foi arquivada.

Em 2005, atendendo a uma das diretrizes da Conferência Nacional de Políticas para Mulheres, a Secretaria Especial de Políticas Públicas para as Mulheres propôs a formação de uma Comissão Tripartite, na qual haveria a representação do governo brasileiro, da sociedade civil e do legislativo. ${ }^{5} \mathrm{O}$ papel dessa Comissão era fazer avançar a pauta da descriminalização do aborto e propor um projeto de lei que pudesse ser encaminhado ao Congresso Nacional. A proposta contempla o direito da mulher de interromper a gravidez com até 12 semanas de gestação, em qualquer caso. Foi entregue pela Secretária Especial de Política para as Mulheres, ministra Nilcéia Freire, ao presidente do Supremo Tribunal Federal (STF), ministro Nelson Jobim. O anteprojeto foi apresentado ao Congresso pela Deputada Jandira Feghali (PcdoB/RJ).

Este processo seguiu emoldurado pelo embate político entre as posições abolicionistas do crime de aborto e as conservadoras, capitaneadas pela Conferência Nacional dos Bispos do Brasil (CNBB). Os bispos da entidade encaminharam uma "carta pelo direito à vida" ao presidente Lula e aos presidentes; do Senado, Renan Calheiros (PMDB/AL); da Câmara dos Deputados, Severino Cavalcanti (PP/PE),

\footnotetext{
5 A comissão tripartite se instalou no dia 6 de abril, com a seguinte composição: seis representantes do Poder Executivo (SPM, Ministério da Justiça, Ministério da Saúde, Casa Civil, Secretaria Nacional de Direitos Humanos e Presidência da República), seis representantes do Congresso Nacional (os senadores Eduardo Suplicy do PT-SP, João Capiberibe do PSB-AP e Serys Slhessarenko do PT-MT; e as deputadas Elaine Costa do PTB-RJ, Suely Campos do PP-RR e Ângela Guadagnin do PT-SP) e seis representantes da sociedade civil (Federação Brasileira das Sociedades de Ginecologia e Obstetrícia, Articulação de Mulheres Brasileiras, Rede Feminista de Saúde, Fórum de Mulheres do Mercosul, Secretaria de Mulheres da CUT e Sociedade Brasileira para o Progresso da Ciência.
} 
e ao ministro da Saúde, Saraiva Felipe. No documento, os religiosos se posicionam contra qualquer forma de aborto.

Em dezembro de 2005, o projeto de lei da descriminalização do aborto sofreu uma primeira derrota na Câmara dos Deputados. Na iminência de vê-lo rejeitado, parlamentares que compõem a CSSF (Comissão de Seguridade Social e Família) decidiram retirá-lo da pauta a fim de modificá-lo e reapresentá-lo. Em comum acordo com o movimento feminista, a estratégia da deputada Jandira Feghali, relatora do projeto, é manter apenas a despenalização, suprimir os artigos 124, 126, 127 e 128 do Código Penal, que tipificam crimes relacionados ao aborto consentido pela gestante, deixando de fora a regulamentação do projeto, inclusive a parte que assegurava o atendimento pelo SUS nos casos de interrupção voluntária da gravidez.

Com a dificuldade de fazer avançar a descriminalização do aborto voluntário, voltaram-se as atenções para a regulamentação do aborto legal. $\mathrm{O}$ debate partiu novamente dos movimentos feministas, chegou à sociedade nacional, passando pelos meios de comunicação social, pelos conselhos Nacional e Regionais de Medicina, pelos juristas, pela Igrejas e desembocaram no Congresso Nacional onde já tramitava o Projeto de Lei no 20, de 1991 - PL20/91. Este projeto, que disciplina o atendimento aos casos de aborto legal no Sistema Único de Saúde, foi aprovado nas Comissões de Seguridade Social e Família e de Constituição, Redação e Justiça da Câmara dos Deputados e aguarda apreciação pelo plenário.

Em junho de 2008, o Projeto de Lei no ${ }^{-1.135 / 91}$ sobre a descriminalização foi rejeitado, após 17 anos de tramitação, pela Comissão de Constituição, Justiça e Cidadania. O projeto pode ainda ser remetido à plenária do Congresso Nacional por solicitação de uma parcela dos deputados federais e, ainda, ser submetido a plebiscito popular.

Outra frente de disputa dá-se no âmbito do Poder Judiciário, especialmente no Supremo Tribunal Federal. Ao julgar a Ação Direta de Inconstitucionalidade $\mathrm{n}^{-}$3.510, que questionava a constitucionalidade do artigo 5o da Constituição Federal, que diz respeito à inviolabilidade da vida humana, esse Tribunal manifestou o entendimento de que somente cabe ao Direito proteger o direito à vida dos já nascidos, tendo em conta que é o nascimento com vida que dá início à personalidade civil. Por outro lado, a Suprema Corte brasileira decidiu pela constitucionalidade da Lei de 
Biossegurança, autorizando a pesquisa com células-tronco embrionárias, abrindo assim espaço para a discussão sobre a descriminalização do aborto.

A reação a essas decisões do Supremo Tribunal Federal veio através da proposição do Estatuto do Nascituro, que inicia tramitação no Congresso Nacional.

O Código Penal brasileiro (Decreto-Lei no 2.848 , de 7 de dezembro de 1940) contempla duas hipóteses para interrupção legal da gestação: quando desta decorre perigo de morte para a gestante e quando a gravidez é decorrente de estupro. ${ }^{6}$

Recentemente, instalou-se no Brasil o debate acerca da interrupção da gestação de fetos anencefálicos. O fato que desencadeou esse debate foi a decisão liminar concedida pelo Ministro Marco Aurélio de Mello, do Supremo Tribunal Federal (STF), autorizando a interrupção da gestação quando detectada anencefalia fetal, por ser este um agravo à saúde incompatível com a vida fora do útero materno.

A anencefalia é uma alteração na formação do sistema nervoso central que decorre de falha no fechamento do tubo neural conhecido como indução dorsal. Essa falha ocorre nas primeiras semanas do desenvolvimento embrionário (em torno do $26^{\circ}$ dia) e resulta na ausência dos hemisférios cerebrais e de ossos cranianos (frontal, occipital e parietais). O tronco cerebral e a medula espinhal estão preservados, salvo quando há também defeitos no fechamento da coluna vertebral (mielomeningocele). Sua incidência no Brasil está estimada em dois por mil nascimentos, segundo a Federação Brasileira das Associações de Ginecologia e Obstetrícia (FEBRASGO). A maioria dos fetos nesta condição tem morte intrauterina, mas estima-se que de cada quatro um nasça com vida, vindo a falecer nas primeiras horas ou dias. ${ }^{7}$

6 O Decreto-Lei no 2.848/1940, art. 128, dispõe que "Não se pune o aborto praticado por médico: I - Se não há outra maneira de salvar a vida da gestante. II - Se a gravidez resulta de estupro e o aborto é precedido de consentimento da gestante ou, quando incapaz, de seu responsável legal".

7 O Projeto de Lei do Senado no 227, de 2004, propõe a alteração do art. 128 do Código Penal para acrescentar o inciso III, contemplando a hipótese de aborto em caso de gravidez de feto com anencefalia. O Projeto de Lei no 660/2007, que tramita apensado ao Projeto de Lei no 1.174/1991, acrescenta inciso ao art. 128 do Código Penal com a finalidade de isentar de pena a prática de "aborto terapêutico" em caso de grave e incurável anomalia do feto, incluindo o anencefálico, que implique na impossibilidade de vida extrauterina. 
Atualmente é possível identificar o problema ainda no início da gravidez, graças ao uso da ultrassonografia obstétrica. Essa informação, na fase inicial da gestação, suscita a indagação sobre a possibilidade de interrupção legal da gestação. Esta hipótese não está contemplada na legislação. No entanto, a decisão do STF concedendo a liminar acima mencionada acendeu o debate nos meios médico e jurídico, com repercussões importantes no Congresso Nacional, onde tramitam projetos de leis que pretendem regular a matéria. ${ }^{8}$

A regulamentação do artigo 128 do Código Penal, de 1940, somente veio a ocorrer através de Norma Técnica expedida pelo Ministério da Saúde, em 1998, que trata da "Prevenção e tratamento dos agravos resultantes da violência sexual contra as mulheres e adolescentes". ${ }^{9}$

$\mathrm{O}$ aspecto que vem gerando controvérsia entre parlamentares no Congresso Nacional diz respeito à não exigência do exame de corpo de delito no caso de gravidez decorrente de estupro.

Desde a edição da Norma Técnica, vêm ocorrendo iniciativas no Congresso Nacional que têm como finalidade sustar a sua aplicação, sob a alegação de que não requer a prova da ocorrência do estupro do qual decorre a gravidez, e que o Ministério da Saúde teria alterado o sentido do artigo 128 do Código Penal ao dispensar o exame de corpo de delito.

Outro argumento presente nesse debate é de que a iniciativa do Ministério da Saúde viria a facilitar a prática do abortamento, ao instruir os hospitais do SUS a realizá-lo mediante a solicitação da gestante ou de seu representante legal e do Boletim de Ocorrência Policial. Paira sobre a Norma Técnica a suspeita de que viria a facilitar o recurso ao abortamento legal como "método contraceptivo".

8 Neste texto, utiliza-se a 2o Edição da Norma Técnica, de agosto de 2002. A Norma Técnica estabelece parâmetros para a organização da atenção a mulheres que sofreram violência sexual quanto aos temas: área física, recursos humanos, equipamentos e instrumental demandado, aparelhos adicionais sugeridos, apoio operacional, registro de dados, sensibilização e treinamento de equipes multidisciplinares e organização e divulgação da Rede Integrada de Atendimento. Também trata dos cuidados médicos e de enfermagem relacionados à coleta de material para identificação do agressor, anticoncepção de emergência e quimioprofilaxia para infecção pelo HIV e outras DSTs após violência sexual.

9 Nesse argumento, fundamenta-se, por exemplo, o Projeto de Decreto Legislativo no $\mathbf{0}$, de 2007, que visa a sustar a aplicação da Norma Técnica. 
Constata-se nesses argumentos, sustentados sobretudo pela frente parlamentar que se posiciona contrariamente ao reconhecimento dos direitos reprodutivos das mulheres, desconhecimento sobre a realidade da violência sexual no Brasil. A maior parte das ocorrências de estupro não é registrada na polícia e não é seguida de exame de corpo de delito. Quando a violência sexual é doméstica ou intrafamiliar, geralmente o fato somente se torna conhecido após violência reiterada, ou ainda quando ocorre a gravidez. Quando o estupro é notificado e a vítima é imediatamente atendida na Delegacia da Mulher, medidas profiláticas são adotadas para evitar a gravidez (como a pílula do dia seguinte) e a contaminação por doenças sexualmente transmissíveis.

O debate prossegue nas instâncias jurídico-políticas brasileiras e na sociedade civil, agora com importantes contribuições da Secretaria Especial de Políticas para as Mulheres, que procura subsidiá-lo com informações mais qualificadas.

Enquanto isso, a lacuna na determinação e implementação dos Direitos Reprodutivos e dos Direitos Sexuais tem graves consequências para a vida dos brasileiros e das brasileiras, levando-se em conta que sexualidade e reprodução são determinantes das relações sociais e da vida política, na medida em que interferem significativamente na forma como homens e mulheres, mulheres e mulheres, homens e homens interagem nas instituições e sociedades. Ao definir e institucionalizar direitos reprodutivos e direitos sexuais instituem-se direitos e deveres que passam a ser regulados por leis, permitindo que sejam cobrados pelos cidadãos junto aos órgãos governamentais e vice-versa, assim como entre os cidadãos e suas instituições. Somente a partir dessa institucionalização, os tais direitos passam a fazer parte efetiva dos direitos humanos, elemento fundante e imprescindível de toda e qualquer teoria política moderna (CORRÊA, 1995).

\section{Referências}

ÁLVARES, Sônia. Women's Participation in the Brasilian People's Church: a critical Appraisal. In: Feminist studies 16, n. 2, 1990. p. 381-409. 
ÁVILA, Maria Betânia; GOUVEIA, Taciana. Notas sobre direitos reprodutivos e direitos sexuais. In: PARKER, Richard; BARBOSA, Regina Maria (Org.). Sexualidades brasileiras. Rio de Janeiro: Relume Dumará/ABIA/IMS/UERJ, 1996. p. 160-173.

ÁVILA, Maria Betânia; CORRÊA, Sônia. O movimento de saúde e direitos reprodutivos no Brasil: revisitando percursos. In: GALVÃO, Loren; DÍAZ, Juan (Org.). Saúde sexual e reprodutiva no Brasil. São Paulo: Ed. Population Council, 1999.

BARSTED, Leila. Família, sexualidade e reprodução no direito brasileiro. In: GIFFIN, Karen; COSTA, Sara Hawker (Org.). Questões da saúde reprodutiva. Rio de Janeiro: Fiocruz, 1999. p. 51-66.

CONSELHO NACIONAL DOS DIREITOS DA MULHER. IV

Conferência Mundial sobre a Mulher. Rio de Janeiro: Editora Fiocruz, 1996.

CORRÊA, Sônia; PETCHESKI, Rosalind. Direitos sexuais e reprodutivos: uma perspectiva feminista. Physis: Revista de Saúde Coletiva. v. 6, n. 1-2. Rio de Janeiro, 1996, p. 149-175.

CORRÊA, Sônia. Saúde reprodutiva, gênero e sexualidade: legitimação de novas interrogações. In: GIFFIN, Karen; COSTA, Sara Hawker (Org.). Questões da saúde reprodutiva. Rio de Janeiro: Fiocruz, 1999.

CORRÊA, Sônia. A formulação do conceito: passado e presente. In: Atualidade em debate: reprodução humana e sexualidade. Perspectivas éticas e enfoques cristãos. Caderno 34. Rio de Janeiro: Centro João XIII/ IBRADES, 1995. p. 11-22.

CORRÊA, Sônia (Org.). Direitos tardios: saúde, sexualidade e reprodução na América Latina. São Paulo: Fundação Carlos Chagas: Editora 34, 1997.

BOLETIM FEMEA. Projeto tenta barrar a Norma Técnica sobre aborto. Brasília: Cfemea, Ano VI, n. 71, Dezembro1998.

BOLETIM FEMEA. Os direitos das mulheres e o Legislativo no Brasil. jan. 1999. Brasília, 16p.

GALVÃO, Loren. Saúde sexual e reprodutiva, saúde da mulher e saúde materna: a evolução dos conceitos no mundo e no Brasil. In: GALVÃO, 
Loren; DÍAZ, Juan (Org.). Saúde sexual e reprodutiva no Brasil. São Paulo: Ed. Population Council, 1999.

HERVIEU-LEGER, Daniele. O bispo, a Igreja e a modernidade. In: LUNEAU, René; MICHAEL, Patrick (Org.) Nem todos os caminhos levam à Roma. Petrópolis: Ed. Vozes, 1999.

KYRIAKOS, N. J. (colaboração Adriana Gragnani). n. 37, jun. 1992. Aspectos éticos e legais do aborto no Brasil. Procuradoria Geral do Estado de São Paulo. Centro de Estudos.

PETCHESKY, Rosalind. Direitos sexuais: um novo conceito na prática política internacional. In: BARBOSA, R; PARKER, R (Org.). Sexualidades pelo avesso. Rio de Janeiro: IMS/UERJ, Editora 34, 1999. PETCHESKY, Rosalind. Abortion and women's choice: the state,sexuality, and reproductive freedom. Rev. ed. Boston, Massachusetts: Northeastern University Press, 1994.

PITANGY, Jacqueline. Saúde reprodutiva e população. As novas perspectivas a partir do Cairo. In: CIM. Mulher, População e Desenvolvimento. In: Cadernos do cimo. n.1. 1994.

PITANGUY, Jacqueline. A visita do Papa ao Brasil. Revista de estudos feministas, Rio de Janeiro, v. 5, n. 2, p. 403-405, 1997.

ROCHA, Maria Isabel Baltar. Política demografia e parlamento. Tese (Doutorado em Ciências Humanas) - Universidade Estadual de Campinas, UNICAMP, São Paulo, 1992.

RUBIN, Gayle. Reflexionando sobre el sexo: notas para una teoría radical de la sexualidad. In: VANCE, Carol. Placer y peligro: explorando la sexualidad femenina. México: Ed. Revolución, 1989.

SANTIN, Myriam Aldana. Aborto legal: Igreja Católica e Congresso Nacional. São Paulo: Publicações CDD, Caderno n. 6, 2000.

SANTOS, Boaventura de Sousa. Por uma concepção multicultural de Direitos Humanos. In: Lua Nova - Revista de Cultura Política. Florianópolis: UFSC, n. 39, p. 105-123, 1997.

SEN, Guita. Conferência do Cairo: Processo e resultados. Um primeiro balanço. Cadernos do CIM. Rio de Janeiro, n. 1, 1994. 